\title{
SURGICAL OUTCOME OF ADDING PLATELET RICH PLASMA ON UNDERLAY MYRINGOPLASTY FOR ANTERIOR TYMPANIC MEMBRANE PERFORATION
}

\author{
By \\ Osama Mohamed Refaat \\ Otorhinolaryngology Department, Faculty of Medicine, Al-Azhar University, Cairo \\ E-mail: osamarefaat78@gmail.com
}

\begin{abstract}
Background: Surgical closure of anterior tympanic membrane perforation (ATMP) has poor outcome due to many reasons as reduced vascular supply, limited anterior margin, poor visualization, and inadequate graft stabilization. Platelet Rich Plasma (PRP) can be defined as an autologous concentration of human platelets in a small volume of plasma.
\end{abstract}

Objective: To evaluate the effect of adding PRP on healing of ATMP by using underlay technique myringoplasty.

Patients and Methods: A prospective randomized study included 40 patients with chronic dry ATMP, attending the ENT outpatient clinics of Al-Azhar University Hospitals between June 2015 and Aug 2016. They were randomly divided into two equal groups: Study group underwent underlay myringoplasty by temporalis facia graft with adding PRP, and control group underwent underlay myringoplasty with only temporalis facia graft. Patients were seen 1, 2, 3 months after surgery.

Results: In the study group, 70\% were males and 30\% were females, and in control group 55\% were males and $45 \%$ were females, with a mean age of $35.1 \pm 5.7$ years in study group, and $32.6 \pm 7.6$ years in the control group. In study group complete healing of perforation was $85 \%$, reduction of perforation size was $10 \%$ and failure of healing was $5 \%$, whereas in control group complete healing of perforation was $45 \%$, reduction of perforation size was $15 \%$ and failure of healing was $40 \%$.

Conclusion: Addition of PRP to fascia graft and using underlay technique myringoplasty increase the incidence of healing of ATMP with decrease post-operative complication.

Key Words: Platelet rich plasma, anterior tympanic membrane perforation, underlay technique, post auricular approach, myringoplasty.

\section{INTRODUCTION}

Tympanic membrane is a thin (approximately $0.1 \mathrm{~mm}$ ) and ovoid structure, separates the external from the middle ear, so it protects the middle ear cleft from potential infections, it also has a role in sound transmission and amplification, as it vibrates when encounters sounds then transmits these vibrations to the ossicles of the middle ear to be further passed on to the cochlea of the inner ear for transduction. Tympanic membrane perforation (TMP) either posttraumatic or post- inflammatory (otitis media) leads to conductive hearing loss (CHL) associated with recurrent middle ear infections with subsequent ear discharge, so closure of the TMP may be 
needed in persistent cases (Park et al., 2015).

Successful closure of anterior tympanic membrane perforation (ATMP) considered challenging. Reasons for poor surgical outcome includes, reduced vascular supply, limited anterior margin, poor visualization and inadequate graft stabilization (Eren et al., 2015).

Myringoplasty involves reconstruction of TMP in the presence of an intact ossicular chain and would result ultimately in normal postoperative hearing. It has different approaches either (post-auricular, endaural or permeatal) and techniques either (overlay or underlay) all seek to increase the probability for the operation's success (Barake et al., 2019).

Platelets are cytoplasmic fragments of megakaryocytes, formed in the bone marrow and approximately $2 \mu \mathrm{m}$ in diameter. They contain more than thirty bioactive proteins, many of which have a fundamental role in hemostasis and/or tissue healing (Rachita and Sukesh, 2016).

Seven protein growth factors effectively secreted by platelets activate all wound healing processes which are platelet derived growth factor (PDGF), transforming growth factor (TGF), vascular endothelial growth factor, (VEGF), epidermal growth factor, (EGF), fibroblast growth factor, (FGF), connective tissue growth factor (CTGF) and insulin-like growth factor - 1 (IGF-1). Moreover platelet rich plasma (PRP) contains 3 protein molecules known to act as cell adhesion molecules that are fibrin, fibronectin and vitronectin. PRP also rich in leukocytes that acts as bactericidal for any infection (Cole et al., 2010).
PRP was developed in the 1970s then in 1987s; Ferrari et al. used it for the first time in cardiothoracic surgery. In the mid1990s PRP therapy became popular used in many medical and surgical fields as it has been safe and effective (Oliver and Crane, 2010).

The present work aimed to evaluate the effect of adding PRP on healing of ATMP by using underlay technique myringoplasty.

\section{PATIENTS AND METHODS}

This prospective randomized study was performed on 40 patients presented by dry ATMP, attended ENT outpatient clinics of Al-Azhar University Hospitals during the period between June 2015 and Aug 2016. This study was approved by the local Ethics and Research Committee of Faculty of Medicine, Al-Azhar University. A written consent was obtained from all patients after providing detailed information to the recruited patients. Patients were randomly divided into two equal groups: Study group where patients did underlay myringoplasty by temporalis facia graft with adding PRP, and control group who did underlay myringoplasty with temporalis facia graft only. Full history taken included systemic and ENT history with focusing on onset, course, duration of perforation, associated hearing defect, last time of ear discharge and its character regarding to frequency, color and odor. Full ENT examination included nasal and nasopharyngeal examination, otoscopic and microscopic examination of the affected ear regarding to site, size of perforation, associated ear discharge or anterior bony overhang. Audio logical assessment (pure tone audiogram with tympanometry).

Laboratory 
investigations included $\mathrm{CBC}$, FBS, prothrombin time (PT), Partial thromboplastin time (PTT), international normalized ratio (INR), clotting time, bleeding time, liver and kidney functions. Inclusion criteria those with ATMP should be dry for at least 4 weeks before surgery and presence of the perforation for at least 3 months, all patients have only CHL. Exclusion criteria those with recently active ears discharge, failed previous myringoplasty, cholesteatoma; patients have any ossicular problems or mixed hearing loss, autoimmune and hematologic diseases, and immunosuppressive treatment.

Under general anesthesia with operative microscopy all patients underwent post auricular approach with underlay myringoplasty technique using temporalis fascia graft. In study group, small pieces of impregnated gelfoam with PRP placed in the middle ear cavity under fascia graft, then additional soaked gelfoam pieces with PRP placed in the external canal lateral to the graft. In control group dried small pieces of gelfoam placed in the middle ear cavity under fascia graft, other dry pieces of gelfoam placed in the external canal lateral to the graft. In both groups posterior tympanomeatal flap returned back to its position, ear wick painted with fusidic acid put in the external ear canal then wound closure done.
All patients received systemic antibiotic and analgesic for 7 days, they followed up for hearing evaluation, assessment healing of perforation and if there is complications within the next 1,2 , 3 months post-operatively. $\mathrm{P}$ value less than 0.05 was consider statistically significant.

\section{Statistical Analysis:}

Numerical data were explored for normality by checking the distribution of data and using tests of normality (Kolmogorov-Smirnov and Shapiro-Wilk tests). Age data showed normal (parametric) distribution while audiogram assessment data showed non-parametric distribution. Data were presented as mean, standard deviation (SD), median and range values. For parametric data, Student's t-test was used to compare between mean age values in the two groups. For non-parametric data, MannWhitney $U$ test was used to compare between the two groups. Qualitative data were presented as frequencies and percentages. Chi-square test or Fisher's Exact test when applicable were used to compare between qualitative data in the two groups. The significance level was set at $\mathrm{P} \leq 0.05$. Statistical analysis was performed with IBM SPSS Statistics for Windows, Version 23.0. Armonk, NY: IBM Corp.

\section{RESULTS}

Total 40 patients, study group 14 $(70 \%)$ were males and $6(30 \%)$ were females, while control group $11(55 \%)$ were males and $9(45 \%)$ were females, with a mean age of $35.1 \pm 5.7$ years in study group, and $32.6 \pm 7.6$ years in the control group underwent analysis. There was no statistically significant difference 
either between gender distributions or mean age values in the two groups. Regarding to perforation history: In study group $7(35 \%)$ were right sided ATMP and $13(65 \%)$ were left sided ATMP, with $4(20 \%)$ had anterior bony overhang, whereas in control group $5(25 \%)$ were right sided ATMP and $15(75 \%)$ were left sided ATMP with 5 (25\%) had anterior bony overhang. There was no statistically significant difference either between perforation sides or presence of anterior bony overhang in the two groups (Table 1).

Table (1): Mean, standard deviation (SD), frequencies (n), percentages (\%) and results of Student's t-test, Chi-square test and Fisher's Exact test for comparisons of parameters in the two groups

\begin{tabular}{|c|c|c|c|}
\hline $\begin{array}{ll}\text { Parameters } & \text { Groups } \\
\end{array}$ & $\begin{array}{c}\text { Control group } \\
(\mathbf{n}=\mathbf{2 0})\end{array}$ & $\begin{array}{c}\text { Study group } \\
(\mathbf{n}=20)\end{array}$ & $\begin{array}{c}\text { P- } \\
\text { value }\end{array}$ \\
\hline $\begin{array}{l}\text { Age (year) } \\
\text { Mean (SD) }\end{array}$ & $32.6 \pm 7.6$ & $35.1 \pm 5.7$ & 0.246 \\
\hline \multicolumn{4}{|l|}{ Gender [n (\%)] } \\
\hline Male & $11(55 \%)$ & $14(70 \%)$ & \multirow{2}{*}{0.327} \\
\hline Female & $9(45 \%)$ & $6(30 \%)$ & \\
\hline \multicolumn{4}{|l|}{ Perforation history [n (\%)] } \\
\hline Right & $5(25 \%)$ & $7(35 \%)$ & \multirow{2}{*}{0.490} \\
\hline Left & $15(75 \%)$ & $13(65 \%)$ & \\
\hline Presence of anterior bony overhang & $5(25 \%)$ & $4(20 \%)$ & 1.000 \\
\hline
\end{tabular}

Pre-operatively, mean CHL was $27.3 \pm$ 6.2 in study group, and $24.8 \pm 5$ in control group. There was no statistically significant difference between the two groups. Post-operatively, mean CHL was $6.3 \pm 9.2$ in study group and $13.3 \pm 10.8$ in control group, study group showed statistically significantly lower median score than control group. Regarding to change in audiogram assessment, study group showed statistically significantly higher median reduction in audiogram scores than control group. Study group showed statistically significantly higher median $\%$ reduction in audiogram scores than control group (Table 2).

Table (2): Descriptive statistics and results of Mann-Whitney $U$ test for comparison between audiogram assessment $(\mathrm{dB})$ in the two groups

\begin{tabular}{|c|c|c|c|c|}
\hline $\begin{array}{ll}\begin{array}{l}\text { Audiogram } \\
\text { Assessment (dB) }\end{array} & \text { Groups } \\
\end{array}$ & $\begin{array}{c}\text { Control group } \\
(\mathbf{n}=\mathbf{2 5})\end{array}$ & $\begin{array}{l}\text { Study group } \\
\quad(n=25)\end{array}$ & $\begin{array}{c}P \text { - } \\
\text { value }\end{array}$ & $\begin{array}{c}\text { Effect } \\
\text { size } \\
(d) \\
\end{array}$ \\
\hline \multicolumn{5}{|l|}{ Pre-operative } \\
\hline Median (Range) & $25(15-35)$ & $27.5(15-35)$ & \multirow{2}{*}{0.171} & \multirow{2}{*}{0.444} \\
\hline Mean (SD) & $24.8 \pm 5$ & $27.3 \pm 6.2$ & & \\
\hline \multicolumn{5}{|l|}{ Post- operative } \\
\hline Median (Range) & $15(0-30)$ & $0(0-25)$ & \multirow{2}{*}{0.024} & \multirow{2}{*}{0.698} \\
\hline Mean (SD) & $13.3 \pm 10.8$ & $6.3 \pm 9.2$ & & \\
\hline \multicolumn{5}{|l|}{ Change (dB) } \\
\hline Median (Range) & $-11.5(-30-5)$ & $-22.5(-35-0)$ & \multirow{2}{*}{0.017} & \multirow{2}{*}{0.783} \\
\hline Mean (SD) & $-11.5 \pm 13$ & $-21 \pm 11.2$ & & \\
\hline \multicolumn{5}{|l|}{ Reduction (\%) } \\
\hline Median (Range) & $-40(-100-33.3)$ & $-100(-100-0)$ & \multirow{2}{*}{0.008} & \multirow{2}{*}{0.795} \\
\hline Mean (SD) & $-41.7 \pm 48.4$ & $-76 \pm 37.2$ & & \\
\hline
\end{tabular}


In study group, 17 (85\%) had complete healing of their ear perforations, 2 (10\%) had reduction of perforation size and 1 $(5 \%)$ had failure of healing, whereas in control group, $9(45 \%)$ had complete healing of their ear perforations, $3(15 \%)$ had reduction of perforation size and 8
(40\%) had failure of healing. There was a statistically significant difference between outcomes in the two groups. Study group showed higher prevalence of complete healing and less prevalence of reduction of perforation size and failure of healing than control group (Table 3).

Table (3): Frequencies (n), percentages (\%) and results of Fisher's Exact test for comparison between outcomes in the two groups

\begin{tabular}{|c|c|c|c|c|c|c|}
\hline \multirow{2}{*}{ Outcome } & \multicolumn{2}{|c|}{$\begin{array}{c}\text { Control group } \\
(\mathbf{n = 2 0})\end{array}$} & \multicolumn{2}{c|}{$\begin{array}{c}\text { Study group } \\
(\mathbf{n = 2 0})\end{array}$} & \multirow{2}{*}{$\begin{array}{c}\text { P- } \\
\text { value }\end{array}$} & $\begin{array}{c}\text { Effect } \\
\text { size } \\
(\mathbf{v})\end{array}$ \\
\cline { 2 - 5 } & $\mathbf{N}$ & $\mathbf{\%}$ & $\mathbf{N}$ & $\mathbf{\%}$ & & \multirow{2}{*}{0.017} \\
\hline Complete healing & 9 & 45 & 17 & 85 & \multirow{2}{*}{0.450} \\
\hline Reduction of perforation size & 3 & 15 & 2 & 10 & \\
\hline Failure of healing & 8 & 40 & 1 & 5 & & \\
\hline
\end{tabular}

\section{DISCUSSION}

Many studies were done for repairing chronic central TMP by using PRP as adjunctive with different types of grafts like fat, fascia or perichondrial graft. This study was done to assess the effect of adding PRP to fascia graft on healing of ATMP through underlay technique. ATMP has a point of challenge because of its high failure rate for healing due to many reasons like reduced vascular supply, limited anterior margin, poor visualization, and inadequate graft stabilization (Eren et al., 2015).

Endoscopic trans-canal myringoplasty (Chih-Chieh et al., 2016), loop underlay tympanoplasty (Barake et al., 2019), three-point fix technique (Shim et al., 2015), loop overlay tympanoplasty with a superiorly based tympanomeatal flap and overlay placement of the graft (Lee et al., 2010). All these procedures have been designed to close the ATMP which have a higher success rates compared to the traditional technique, but most of these maneuvers involved different combinations of overlay and underlay techniques, with or without elevation of the anterior part of the annulus for better anchor the graft, which may imply the need for a more experienced surgeon to close perforation at the anterior portion of the TM.

Overlay grafting technique was reported to be more successful in closure of anterior and subtotal perforations; however it is more technically challenging with high risk for post-operative complications, as graft lateralization, blunting, canal stenosis, impaired vascular supply and delayed healing, as well as a higher risk of cholesteatoma formation than the underlay technique (Panchal et al., 2015).

Adipose tissue used as an alternative material for closure TMP but when it applied on large perforations alone noticed that it was resorbed before complete closure was achieved (Niklasson and Tano, 2011). So that, many surgeons restrict the use of fat plug myringoplasty to small-sized perforations (Gun et al., 2016). 
Tamer et al. (2018) reported in their prospective study included forty patients, presented with dry central TMP that using of fat graft myringoplasty with PRP application is highly successful with no reported postoperative infections and minimal morbidity. Ahmed et al. (2018) reported that the result of addition of PRP with fat graft in 20 patients have small to medium sized central TMP, $100 \%$ success rate was obtained in small perforation and $79.3 \%$ in medium sized perforation.

Masoumeh et al. (2018) reported in their double-blind randomized study on patients with chronic TMP underwent tympanoplasty with PRP enriched gel foams that addition of PRP to conventional gelfoam used in TMP repair increases its complete healing rate. Alvaro et al. (2011) reported a $100 \%$ success rate for TMP healing in PRP intervention group.

El-Anwar et al. (2015) demonstrated a positive effect of PRP application on healing of large tympanic membrane perforations. Ruta et al. (2018) reported in their study, using an underlay technique and temporalis facia graft, that when PRP was applied into external auditory canal over the surface of the graft and tympanic membrane remnant, success rate was $100 \%$ of cases.

\section{CONCLUSION}

Addition of PRP to fascia graft and using underlay technique myringoplasty increase the incidence for healing of anterior tympanic membrane perforation with decrease post-operative complication.

\section{REFERENCES}

1. Ahmed R, Yasser A and Magdy B (2018): Myringoplasty of Central Tympanic Membrane Perforation with A Fat Graft From The Ear Lobule And Platelet Rich Plasma. Z.U.M.J., 24(2): 188-192.

2. Álvaro $\mathbf{M}$, Ortiz $\mathbf{N}$ and Rodriguez $\mathbf{L}$ (2011): Pilot study on the efficiency of the biostimulation with autologous plasma rich in platelet growth factors in otorhinolaryngology: Otologic surgery (tympanoplasty type I). ISRN surgery, Vol.2011:1- 4.

3. Barake R, El Natout $\mathbf{T}$ and El Natout $\mathrm{M}$ (2019): Loop underlay tympanoplasty for anterior, subtotal and total tympanic membrane perforations: a retrospective review. Journal of Otolaryngology- Head and Neck Surgery, 48(12): 1- 5.

4. Chih-Chieh T, Ming-Tang $L$ and Chia-Che W (2016): Endoscopic Transcanal Myringoplasty for Anterior Perforations of the Tympanic Membrane JAMA Otolaryngology-Head \& Neck Surgery, 142. (11): 1088- 1093.

5. Cole B, Seroyer $S$ and Filardo G (2010): Platelet-rich plasma: Where are we now and where are we going? Sports Health; 2:203-10.

6. El-Anwar M, El-Ahl $M$ and Zidan A (2015): Topical use of autologous platelet rich plasma in myringoplasty. Arius Nasus Larynx, 42(5):365-8.

7. Eren S, Tugrul $S$ and Ozucer B (2015): Endoscopic transcanal inlay myringoplasty: alternative approach for anterior perforations. Otolaryngol Head Neck Surg., 153:891-893.

8. Gun T, Fatih $O$ and Atan D (2016): Comparison of hyaluronic acid fat graft myringoplasty, fat graft myringoplasty and temporal fascia techniques for the closure of different sizes and sites of tympanic membrane perforations. J. Int. Adv. Otol., 12(2):137-141.

9. Lee H, Auo H and Kang $\mathbf{J}$ (2010): Loop overlay tympanoplasty for anterior or subtotal perforations. Auris Nasus Larynx, 37(2):1626. 
10. Masoumeh S, Mohammad A and Esmaeil Z (2017): The Effect of PRP-enriched Gelfoam on Chronic Tympanic Membrane Perforation: A Double-blind Randomized Clinical Trial. International Tinnitus Journal, 21(2):108-111.

11. Niklasson $A$ and Tano $K$ (2011): The Gelfoam plug: an alternative treatment for small eardrum perforations. Laryngoscope, 121:782-784.

12. Oliver K and Crane D (2010): Platelet rich plasma grafts in musculoskeletal medicine. Journal of Prolotherapy, 2(2):371-6.

13. Panchal V, Gulia J and Yadav S (2015): To evaluate and compare the results of overunderlay graft technique with conventional underlay myringoplasty. Indian J. Otol; 21:274-9.

14. Park H, Hong $S$ and Kim H (2015): De $\neg$ terminants of conductive hearing loss in tympanic membrane perforation. Clin Exp Otorhinolaryngol., 8: 92-6.
15. Rachita D and Sukesh $M$ (2016): Principles and Methods of Preparation of Platelet-Rich Plasma: A Review and Author's Perspective. Journal of Cutaneous and Aesthetic Surgery, 7(4): 189- 197.

16. Ruta S, Yoganathan $G$ and Vellavedu $U$ (2018): Myringoplasty with Autologous Platelet Rich Plasma -A Prospective Study. JMSCR, 10(6): 1170-1173.

17. Shim D, Kim H and Kim M (2015): Threepoint fixes tympanoplasty. Acta. Otolaryngology, 135(5):429-34.

18. Tamer F, Mohamed $H$ and Said E (2018): Effect of adding platelet-rich plasma to fat grafts in myringoplasty. The Egyptian Journal of Otolaryngology, 34:224-228. 


\section{الناتج الجراحي لإضافة بلازما غنية بالصفائح الاموية على الألى الأني

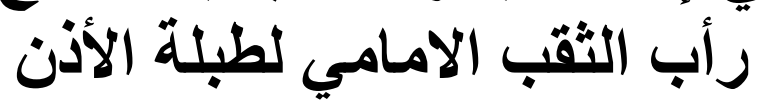 أسامة محمد رفعت الاهي لطايله}

قسم الأنف والأذن والحنجرة، كلية الطب، جامعة الأزهر، القاهرة

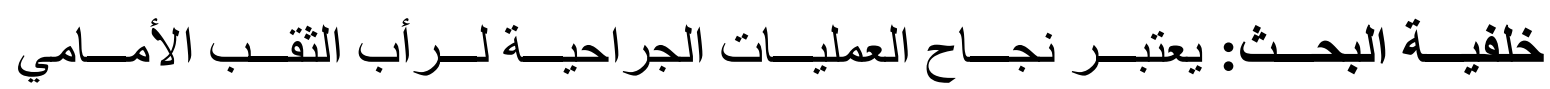

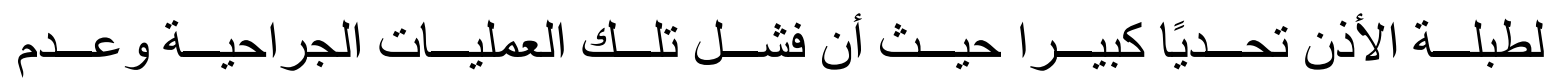

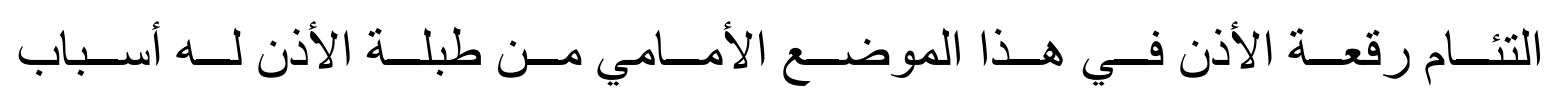

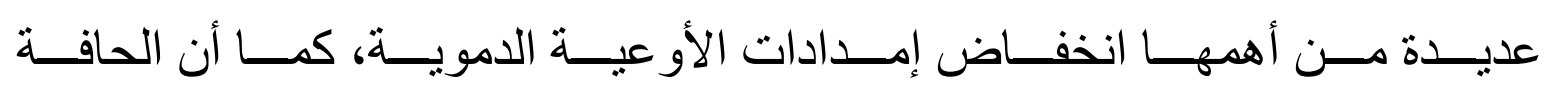

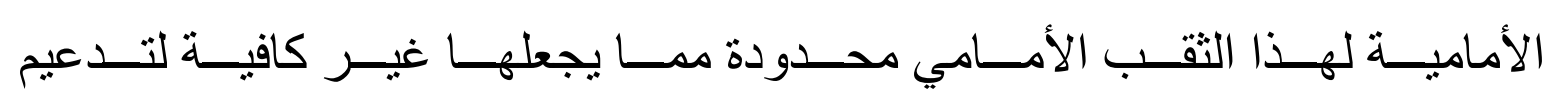

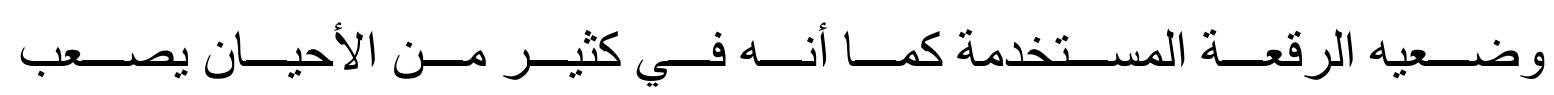

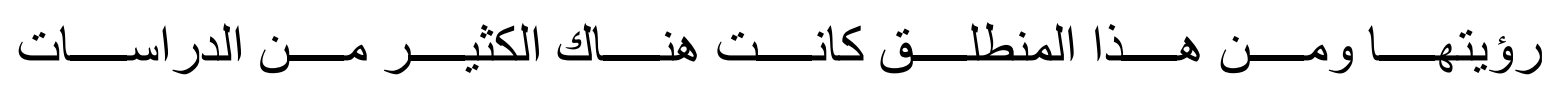

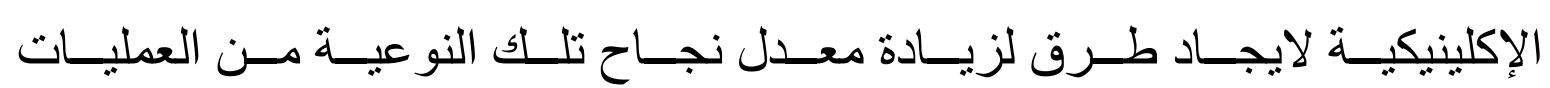
الجر احية.

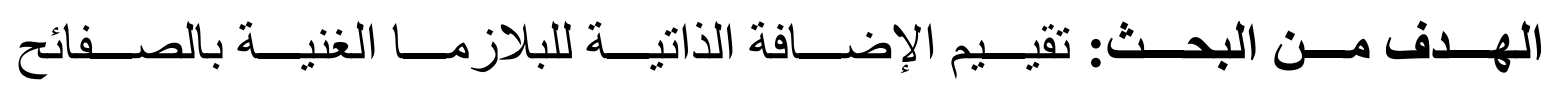
الدموية للمريض علي معدل نجاح رأب التقب الأمامي لطبلة الاذن.

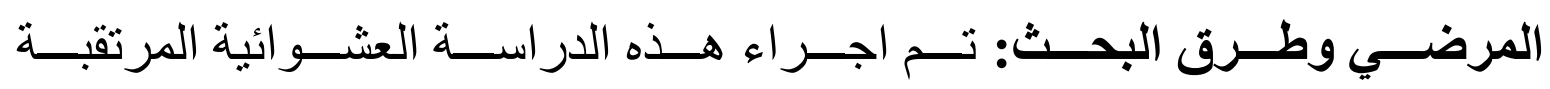

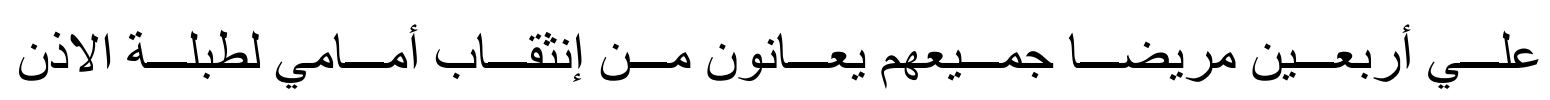

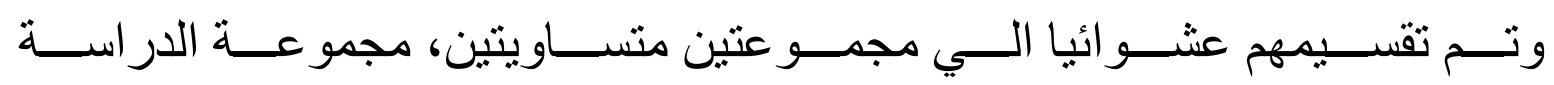

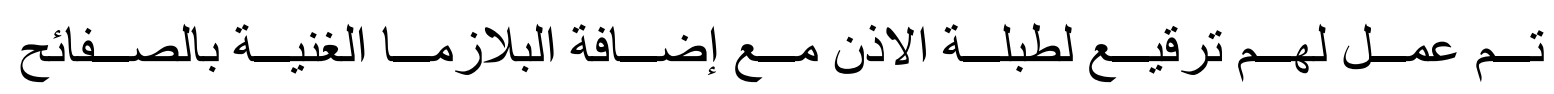

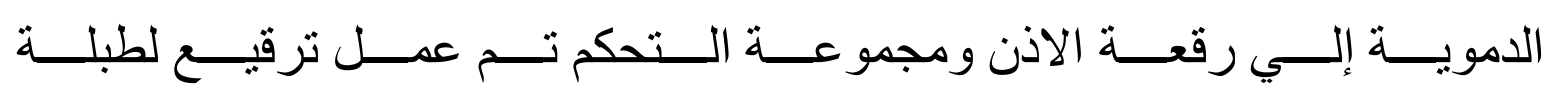
الأذن بدون إضافة البلازما الغنية بالصفائح الدموية. 
SURGICAL OUTCOME OF ADDING PLATELET RICH PLASMA ON...

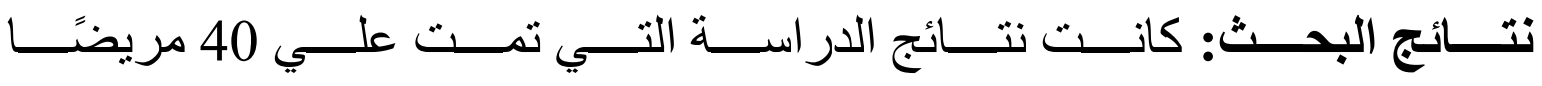

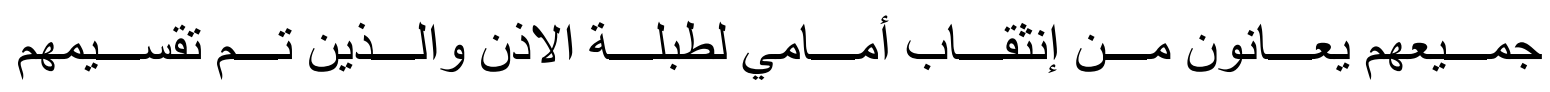

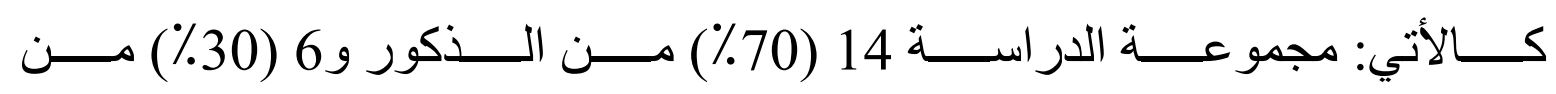

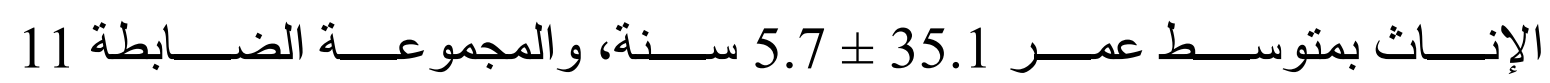

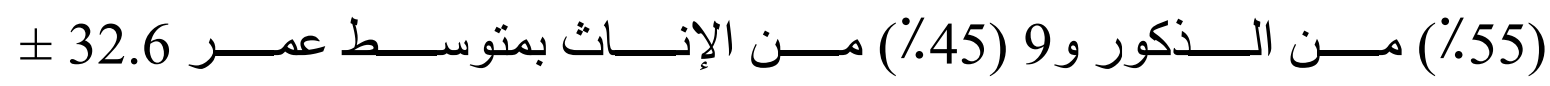

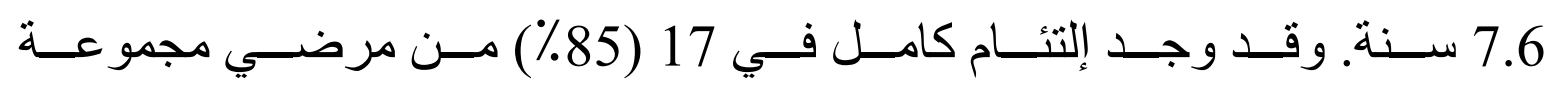

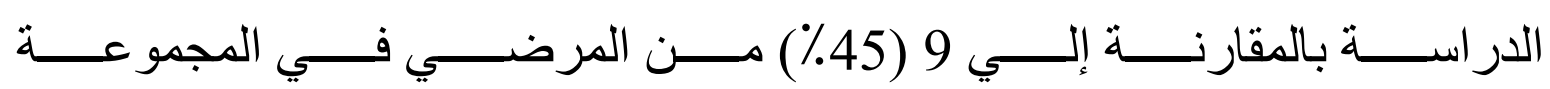

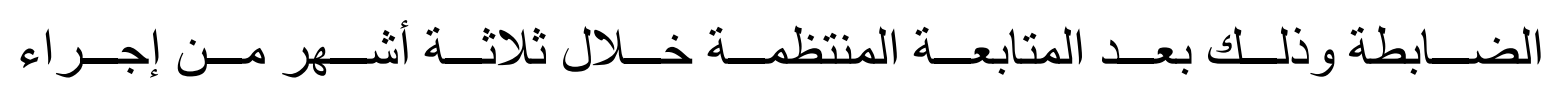
الجراحة.

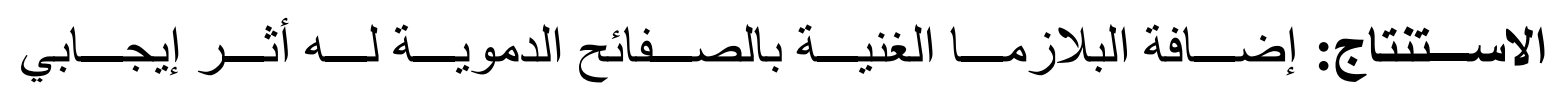

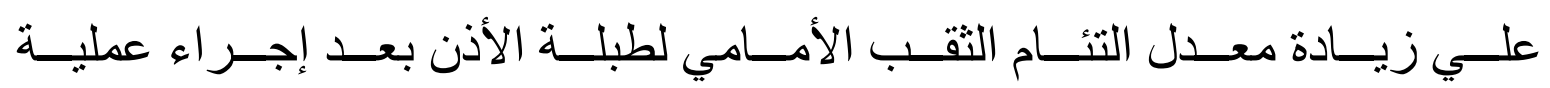
الترقيع. 